\title{
BMJ Open Leveraging ongoing research to evaluate the health impacts of South Africa's salt reduction strategy: a prospective nested cohort within the WHO-SAGE multicountry, longitudinal study
}

\author{
Karen Charlton, ${ }^{1}$ Lisa J Ware, ${ }^{2}$ Elias Menyanu, ${ }^{1}$ Richard Berko Biritwum, ${ }^{3}$ \\ Nirmala Naidoo, ${ }^{4}$ Chiné Pieterse, ${ }^{2}$ Savathree (Lorna) Madurai, ${ }^{5}$ \\ Jeannine Baumgartner, ${ }^{6}$ George A Asare, ${ }^{7}$ Elizabeth Thiele, ${ }^{8}$ Aletta E Schutte, ${ }^{2,9}$ \\ Paul Kowal ${ }^{4,10}$
}

To cite: Charlton K, Ware LJ, Menyanu E, et al. Leveraging ongoing research to evaluate the health impacts of South Africa's salt reduction strategy: a prospective nested cohort within the WHO-SAGE multicountry, longitudinal study. BMJ Open 2016;6: e013316. doi:10.1136/ bmjopen-2016-013316

- Prepublication history for this paper is available online. To view these files please visit the journal online (http://dx.doi.org/10.1136/ bmjopen-2016-013316).

$\mathrm{KC}$ and LJW contributed equally.

Received 4 July 2016 Revised 27 September 2016 Accepted 28 October 2016

CrossMark

For numbered affiliations see end of article.

Correspondence to

Lisa J Ware;

lisa.jayne.ware@gmail.com

\section{ABSTRACT}

Introduction: Attempting to curb the rising epidemic of hypertension, South Africa implemented legislation in June 2016 mandating maximum sodium levels in a range of manufactured foods that contribute significantly to population salt intake. This natural experiment, comparing two African countries with and without salt legislation, will provide timely information on the impact of legislative approaches addressing the food supply to improve blood pressure in African populations. This article outlines the design of this ongoing prospective nested cohort study.

Methods and analysis: Baseline sodium intake was assessed in a nested cohort of the WHO Study on global AGEing and adult health (WHO-SAGE) wave 2 (2014-2015), a multinational longitudinal study on the health and well-being of adults and the ageing process. The South African cohort consisted of randomly selected households $(n=4030)$ across the country. Spot and 24-hour urine samples are collected in a random subsample $(n=1200)$ and sodium, potassium, creatinine and iodine analysed. Salt behaviour and sociodemographic data are captured using face-to-face interviews, alongside blood pressure and anthropometric measures. Ghana, the selected control country with no formal salt policy, provided a nested subsample $(n=1200)$ contributing spot and 24-hour urine samples from the SAGE Ghana cohort $(n=5000)$. Follow-up interviews and urine collection (wave 3 ) in both countries will take place in 2017 (postlegislation) to assess change in population-level sodium intake and blood pressure.

Ethics and dissemination: SAGE was approved by the WHO Ethics Review Committee (reference number RPC149) with local approval from the North-West University Human Research Ethics Committee and University of the Witwatersrand Human Research Ethics Committee (South Africa), and University of Ghana Medical School Ethics and Protocol Review Committee (Ghana). The results of the study will be published in peer-reviewed international journals,

\section{Strengths and limitations of this study}

Rigorous random selection procedure based on a sample designed to be nationally representative.

- Ongoing data collection within the WHO Study on global AGEing and adult health (WHO-SAGE) cohort to capture salt intake and disease.

- We were unable to identify the specific foods contributing to salt intake in wave 2 .

- Results may be less representative for the smaller sample of adults aged 18-49 years.

- Nationwide implementation of salt regulations precludes inclusion of a local control group.

presented at national and international conferences, and summarised as research and policy briefs.

\section{CURRENT STUDY STATUS}

Data collection for wave 2 (baseline for the nested salt substudy) has been completed, while data collection for wave 3 (first follow-up of the nested salt substudy) will take place in 2017 and is estimated to be complete by the end of 2017. Further waves of data collection are planned as part of the multicountry, longitudinal WHO Study on global AGEing and adult health (WHO-SAGE).

\section{INTRODUCTION}

Many adults consume more salt daily than is recommended, contributing to the global epidemic of hypertension and cardiovascular disease (CVD). ${ }^{1}$ In low-income and middle-income countries (LMIC), a disproportionately rapid increase in hypertension is 
occurring without commensurate strategies to halt this growth or mitigate the impact on CVDs and death. ${ }^{2}$ The scale of the problem in South Africa is evident: among six LMICs in one study, South Africa was shown to have the highest prevalence of hypertension $(78 \%)$ in adults aged 50 years and older. ${ }^{3}{ }^{4}$ Public health strategies are being employed to reduce levels of hypertension, including over 30 countries using legislative changes as part of their salt reduction strategy to meet the WHO and World Health Assembly salt target of $30 \%$ reduction in population salt/sodium intake by $2025 .^{56}$

South African researchers found that nondiscretionary salt intake (salt already in processed foods) is estimated to contribute around $60 \%$ of the overall daily salt intake, primarily from bread and meat products. $^{7}$ As a result of this research, in March 2013 South Africa was the first country to legislate for mandatory reformulation of a range of foods, ${ }^{8}$ setting maximum sodium levels ( $\mathrm{mg}$ per $100 \mathrm{~g}$ ) in targeted processed foods (bread $400 \mathrm{mg}$; breakfast cereal $500 \mathrm{mg}$; butter and margarine $550 \mathrm{mg}$; potato crisps $650 \mathrm{mg}$; salty snacks $800 \mathrm{mg}$; raw sausage $800 \mathrm{mg}$; processed meat $850-950 \mathrm{mg}$; instant noodle mix $1500 \mathrm{mg}$; dry soup powder $5500 \mathrm{mg}$; and stock concentrate $18000 \mathrm{mg}$ ), all identified as contributing significantly to sodium intake in the South African population. ${ }^{7910}$ The first phase of sodium legislation was implemented in June 2016, with further reductions required in sodium levels across food categories by June 2019. ${ }^{11}$ The legislation is predicted to decrease nationwide salt intake by $0.85 \mathrm{~g} /$ day; ${ }^{12}$ reduce annual CVD deaths by $11 \%$; save the government US $\$ 51.25$ million/year and prevent 2000 cases of poverty annually as a result of saving households more than US $\$ 4$ million/year in out-of-pocket medical expenses. ${ }^{13}$

A number of collateral issues arise regarding salt intake, such as salt being the main source of iodine fortification, so that successful campaigns to reduce salt intake would have the potential to result in reduced iodine intake. ${ }^{14}$ Another consideration is that dietary sodium-to-potassium ratio may predict CVD mortality better than sodium intake alone. ${ }^{15}$ Additionally, debate continues on the efficacy of legislative versus nonlegislative approaches to population salt reduction, 81617 including the mechanisms to monitor and enforce such legislation. ${ }^{18}$ From a public health perspective, the major challenge is to evaluate the effects on population health. This paper discusses one effort undertaken to assess a number of health impacts following the sodium legislation in South Africa in comparison to Ghana, an African country with no sodium legislation, through implementation of a large health study in each country.

\section{METHODS AND ANALYSIS}

\section{Objectives of the research}

The primary aim of this study is to evaluate the impact of the sodium legislation on population sodium intake and blood pressure (BP). Secondary objectives are to assess: (1) the relationship between sodium and potassium levels and BP prelegislation and postlegislation; (2) the impact of the sodium legislation on population iodine intake; and (3) the use of spot urine samples as a proxy for 24-hour urine sample collection to measure population salt excretion in a nested biochemical analysis.

\section{Theory of change}

In order to evaluate the impact of policy on the desired outcome, it is critical to appreciate the steps required between policy implementation and change in the outcome. Gertler et $a l^{19}$ refer to this as the theory of change (how an intervention is supposed to deliver the required results) and propose various models that can be used for this purpose. One of these models, 'the Results Chain', has been adapted for our purposes (figure 1) to explore the causal logic underlying the expectation that sodium legislation will impact BP and CVD. The model shows the inputs (legislation and education), activities (food industry formulation changes; also with monitoring of educational/media activities), outputs (change in sodium levels in foods; changes in awareness about dietary salt and hypertension from any educational activities) and outcomes (reduced dietary intake and urinary excretion of salt, reductions in BP, and finally, reductions in CVD mortality, morbidity and associated healthcare spending).

Inputs, activities and outputs collectively describe the implementation of the legislation and activities planned by the South African National Department of Health $(\mathrm{NDoH})$ and others. These are the subject of monitoring and process evaluation. The outcomes (results) are the subject of impact evaluation and the main focus of this study. However, the impact evaluation needs to be informed by an assessment of the implementation in order to correctly interpret the results. ${ }^{19}$ For example, without knowing whether the targeted food products comply with the legislation, it would be difficult to attribute change in salt intake to the sodium legislation. As such, a multidisciplinary group including the $\mathrm{NDoH}$ will be undertaking these assessments, with contributions from the SAGE collaboration. Gertler et $a l^{19}$ also suggest that development of the Results Chain model promotes exploration of these assumptions and risks within the proposed causal logic. The assumptions and risks are further explored within the discussion.

\section{Ghana as a comparison group}

Gertler $e t a l^{19}$ also recommend including a comparison group. Ideally, this would be a South African group matched on all characteristics and exposures but not affected by the legislation, with data collected at the same time as those who would be affected by the legislation. However, since the legislation is in force across the whole country, this is not possible. Neighbouring countries such as Lesotho, Swaziland, Botswana, etc, would also not be good candidates for a comparison group as 
Figure 1 Results Chain mode for the SAGE nested salt substudy. Note: adapted from Gertler et al. ${ }^{19}$ *Discretionary and non-discretionary salt use.

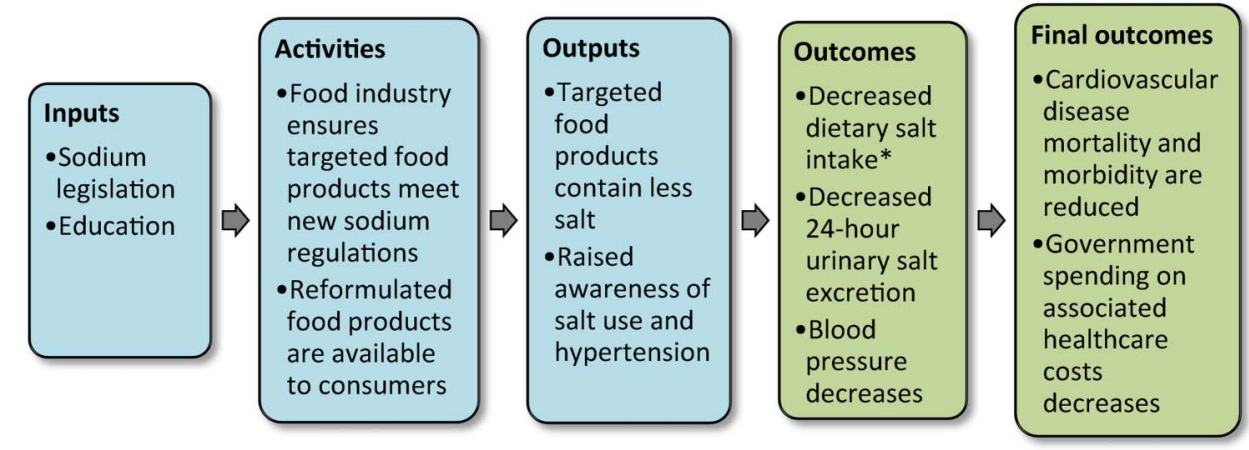

Implementation many of the South African food manufacturers export goods to these countries under the South African Development Community (SADC) Regional Free Trade agreement (2008). South Africa is the major source of processed snack food in the SADC region, ${ }^{20}$ providing around $80 \%$ of the processed food in Zambia, Namibia and Botswana. ${ }^{21}$ These countries then would most likely be affected by the spillover of the South African sodium legislation. SADC countries form over $80 \%$ of South Africa's export market, with exports to the rest of Africa consisting mainly of vehicles and machinery. ${ }^{22}$ As such, Ghana, a non-SADC country and the only other African country to implement WHO-SAGE, was selected as the comparator country. Ghana's adult population is also afflicted by a high prevalence of hypertension (up to $48 \%$ of adults generally ${ }^{23}$ and $54 \%$ of adults $50+$ years of age), increasingly poor risk factor profiles (diet, obesity, physical activity), and poor rates of hypertension awareness and control. ${ }^{3}$ In terms of salt intake, the Ghana Health Service has focused primarily on eradication of iodine deficiency through salt iodisation and education. ${ }^{24}$ At the same time, efforts are underway to boost the salt production industry in Ghana as a method of economic development. ${ }^{25} 26$ Salt intakes appear comparable between Ghana and South Africa with studies suggesting that both countries have intakes between 2.3 and $5.5 \mathrm{~g}$ sodium/day (equivalent to $5.8-13.8 \mathrm{~g}$ salt/day), and higher intakes in urban compared with rural populations. $^{27}$ While there have been some efforts to lower salt intake in community interventions, ${ }^{28}$ until now there appears little evidence to suggest that either mandatory or voluntary sodium targets exist between government and the food industry in Ghana to promote a reduction in population salt intake. However, as in South Africa, it will be critical to monitor activities in Ghana that could influence salt intake between waves 2 and 3 of data collection. There are some risks in taking this pragmatic approach, although local experts will provide ongoing and active assessments in both countries between study waves, and this study team will undertake rigorous comparisons of the nested study groups at waves 2 and 3 to determine the feasibility of this research strategy.

\section{Study population}

\section{Random sampling procedure}

WHO-SAGE is a multinational study examining the health and well-being of adult populations and the ageing process. Two waves of this longitudinal study have been completed in China, Ghana, India, Mexico, Russia and South Africa. ${ }^{29}$ Further details about WHO-SAGE can be found via the WHO website (http://www.who. int/healthinfo/sage/cohorts/en/) including access to data from SAGE wave 0 (2002-2004), SAGE wave 1 (2007-2010) and SAGE wave 2 (2014/2015) following the completion of data cleaning. SAGE wave 3 will be implemented in 2017, with fund-raising for SAGE wave 4 and beyond ongoing. Evaluation of the health effects of this sodium policy on South African adults, in comparison to Ghanaian adults, is conducted using a nested study design in waves 2 and 3, with monitoring of the nested cohort continuing in subsequent waves of data collection.

In total, 42464 respondents were recruited across the six countries for wave 1 (2007-2010), including 4223 respondents in South Africa (9\% 18-49 years; $40 \%$ 5059 years; $51 \% 60+$ years). Wave 1 respondents were recruited from selected probability sampled enumeration areas (EAs) using a multistage cluster sampling strategy, with stratification by province, residence and race.

The wave 2 sampling strategy was designed to account for expected attrition as a result of participants having moved house or died since wave 1 , especially given that over half of the sample were already above 60 years of age in 2007. All wave 1 households were visited for wave 2 data collection (including a verbal autopsy for those participants no longer alive). Replacements for sample attrition used a systematic sampling approach to randomly select new households using EA aerial 
photographic maps on which dwellings are clearly visible, starting at a random point on the periphery of the EA and following predetermined routes. Households were then classified into the following mutually exclusive categories: (1) SAGE wave 1 follow-up households with one or more members aged 50 years or older targeted for selection; (2) new households with one or more members aged 50 years or older; (3) SAGE wave 1 follow-up households which include residents aged 18-49 targeted for selection or (4) new households which include residents aged 18-49. Younger adults are allowed to 'age-in' to the older adult group, with targeted refreshing of the youngest ages (18-23) in the younger adult sample.

The sampling method used in SAGE Ghana wave 2 followed a similar design, based on the 2003 World Health Survey/SAGE wave $0^{30}$ with primary sampling units (PSUs) stratified by region and location (urban/ rural). Selection of the PSUs was based on proportional allocation by size using the same follow-up and random systematic sampling method as South Africa.

\section{Selection and data collection in the nested cohort}

Both South Africa and Ghana include between 3500 to 4500 households for SAGE's main survey sample. The samples selected for urine collection $(n=1200$ in each country) from waves 2 and 3 of the main study are of adults aged 18+ years, with the final distribution in the main and nested studies reflecting the weighting towards recruiting more adults aged 50+ years. In South Africa, the nested study respondents were sampled from among the first wave 2 households visited within each probability sampled EA (day 1 in the EA). This approach was taken to prioritise the shipment of all collected urine samples to a central laboratory (Global Clinical and Viral Laboratory, Durban) within 3 days of collection while maintaining a cold chain regardless of where urine collection took place. This was necessary as there were no decentralised facilities available to freeze urine. The SAGE South Africa team used 20 survey teams (one nurse and three interviewers per team) simultaneously collecting data and urine/blood samples from respondents across all provinces in the country over a 5-month period (August to December 2015).

Selection of the nested study sample in Ghana differed slightly from the one in South Africa. All urine samples were collected by just four fieldwork teams (one research assistant and four interviewers per team) moving region to region over a 10-month period (September 2014 to June 2015). To facilitate this approach, EAs were randomly selected, with stratification by urban/rural, from the three geographical areas (savannah, forest and coastal) of Ghana and designated 'urine EAs' from which the target 1200 respondents were recruited.

Inclusion criteria for urine collection were: respondent must be part of the WHO-SAGE cohort, with no indication of urinary incontinence or other condition that could impede 24-hour urine collection; and if female, not menstruating, pregnant or breast feeding on the day of collection. All respondents who provided samples in wave 2 will be approached again in wave 3 in both countries, with procedures as described earlier for replacement and refreshment of the sample.

\section{Study measures included in WHO-SAGE}

All survey teams are trained with support from WHO Geneva, with survey teams using standardised household, individual and proxy questionnaires, anthropometry, blood sampling, BP and physical function tests as described previously in SAGE wave $1 .^{29}$ Study measures are listed in table 1 and translation and back-translation protocols are in place for the survey instruments. Interviewers speak the respondents' home languages with consent forms available in the most widely spoken languages for each area.

Table 1 Primary and secondary outcome measures

\begin{tabular}{|c|c|c|}
\hline Variable & $\begin{array}{l}\text { Primary/ } \\
\text { secondary } \\
\text { outcome }\end{array}$ & $\begin{array}{l}\text { Method of } \\
\text { measurement }\end{array}$ \\
\hline Sodium intake & Primary & $\begin{array}{l}\text { 24-hour urinary sodium } \\
\text { excretion }\end{array}$ \\
\hline Blood pressure & Primary & $\begin{array}{l}\text { Validated, automated } \\
\text { wrist BP monitor- } \\
\text { triplicate measure }\end{array}$ \\
\hline $\begin{array}{l}\text { Potassium } \\
\text { intake }\end{array}$ & Secondary & $\begin{array}{l}\text { 24-hour urinary } \\
\text { potassium excretion }\end{array}$ \\
\hline lodine status & Secondary & $\begin{array}{l}\text { Urine iodine } \\
\text { concentration }\end{array}$ \\
\hline $\begin{array}{l}\text { Cigarette } \\
\text { smoke } \\
\text { exposure }\end{array}$ & Secondary & $\begin{array}{l}\text { Urine cotinine } \\
\text { concentration and } \\
\text { questionnaire }\end{array}$ \\
\hline Medication use & Secondary & Questionnaire \\
\hline $\begin{array}{l}\text { Dietary salt } \\
\text { behaviour }\end{array}$ & Secondary & Questionnaire* $^{*}$ \\
\hline $\begin{array}{l}\text { Alcohol } \\
\text { consumption }\end{array}$ & Secondary & Questionnaire \\
\hline $\begin{array}{l}\text { Physical } \\
\text { activity }\end{array}$ & Secondary & $\begin{array}{l}\text { Global Physical Activity } \\
\text { Questionnaire }^{44}\end{array}$ \\
\hline $\begin{array}{l}\text { Body } \\
\text { composition }\end{array}$ & Secondary & $\begin{array}{l}\text { Height, weight, waist } \\
\text { and hip circumference }\end{array}$ \\
\hline Quality of life & Secondary & $\begin{array}{l}\text { WHO Quality of Life } \\
\text { instrument } \\
\text { (WHOQoL) }{ }^{45}\end{array}$ \\
\hline
\end{tabular}

*The dietary salt questionnaire consists of the following questions: (1) Do you add salt to food at the table? (Always, rarely, sometimes, often, never); (2) In the food you eat at home, salt is added in cooking [always, rarely, sometimes, often, never); (3) How much salt do you think you consume? (Far too much, too much, just the right amount, too little, far too little, don't know, refused); (4) Do you think a high salt diet could cause a serious health problem? (Yes, no, don't know, refused); (5) Do you do anything on a regular basis to control your salt or sodium intake? (Yes, no, don't know, refused).

BP, blood pressure; WHOQoL, WHO Quality of Life instrument. 
Urine collection in the nested study (waves 2 and 3 )

The study protocol used for sodium determination in 24-hour urine samples followed the WHO/Pan American Health Organization (PAHO) guidelines. ${ }^{31}$ Respondents were requested to collect all urine produced for 24 hours, excluding the first pass urine on day 1 , but including the first urine of the following morning (day 2) in a $5 \mathrm{~L}$ plastic container using $1 \mathrm{~g}$ thymol as preservative. The spot sample was collected without preservative from the second urine passed on day 1 (marking the start of the 24-hour collection) and decanted into three $15 \mathrm{~mL}$ Porvair tubes (Porvair Sciences, Leatherhead, UK), then kept in a thermoelectric cooler box powered by the fieldwork vehicles and containing ice packs to maintain a lowered temperature. The 24-hour sample was collected the next morning, total volumes were recorded and aliquots $(4 \times 15 \mathrm{~mL}$ Porvair tubes) generated with all samples then shipped to the laboratory maintaining the cold chain using precooled ice packs as a means to maintain temperature control. When the samples arrived at the laboratory, the cooler box was examined and the temperature of the samples noted and recorded.

Owing to differences in available resources, duration of data collection and logistical challenges presented by each country, Ghana and South Africa used different methods of urine preservation in wave 2. In Ghana, the survey team kept urine samples in hospitals, clinics and health centres with laboratory facilities in the EA in which they were working. Samples were taken on ice to the central university laboratory between the first and fifth days of interviews in each EA. This was necessary as there were limited options and resources for commercial transport of samples within Ghana. Additionally, with Ghana's tropical climate and a smaller fieldwork team than in South Africa, the possibility that samples may stand for longer in a warmer climate prior to collection necessitated the use of $37 \%$ hydrochloric acid ( $\mathrm{HCl}$; AnalaR NORMAPUR) as a preservative added to both the 24-hour (10 mL per $5 \mathrm{~L}$ collection container) and spot urine $(10 \mathrm{~mL}$ per $2 \mathrm{~L}$ collection container) samples.

In South Africa, thymol preservative, a crystalline natural derivative of the thyme plant, is used as it is easier and safer to transport and handle than commonly used liquid acids by the 20 operating fieldwork teams and courier companies, many of which will not transport liquid acids. In both countries, survey teams explain the dangers of the preservatives to respondents, and are trained in handling the preservatives and biological materials. Both thymol and $\mathrm{HCl}$ have been shown to prevent changes in urinary creatinine, sodium and potassium concentrations for up to 5 days. ${ }^{32}$

Incomplete 24-hour urine collections are assumed if: total volume $\leq 300 \mathrm{~mL}$; or creatinine excretion $\leq 4 \mathrm{mmol} /$ day (women) or $\leq 6 \mathrm{mmol} /$ day $(\mathrm{men}) .{ }^{33}$ The use of para-amino benzoic acid (PABA) has been suggested as a more accurate method than creatinine to validate 24-hour urine collection completeness. ${ }^{34}$ However, PABA recovery rate declines with age in respondents older than 30 years. ${ }^{35}$ Considering this together with the increased risk for non-compliance and attrition due to the additional burden of remembering to take the PABA pill 3 days before the urine collection, as discussed in the WHO/PAHO guidelines for sodium determination in 24-hour urine samples, ${ }^{31} \mathrm{PABA}$ is not used in this study.

\section{Urine analysis}

Sodium and potassium were determined using the indirect ion-selective electrode method and creatinine analysed using the standardised urinary Jaffe kinetic method (South Africa: Beckman Coulter Synchron DXC600/800 System; Ghana: BioSystems Analyzer A25). The WHO population target for salt intake is $5 \mathrm{~g}$ salt $(\mathrm{NaCl})$ per day, equivalent to urinary sodium excretion $85 \mathrm{mmol} / 24$ hour. Urinary potassium should be $>70 \mathrm{mmol} / 24$ hour, with a sodium-to-potassium ratio $<1$ shown to be protective for all-cause, cardiovascular and ischaemic heart disease mortality. ${ }^{15}$ With the exception of iodine, all South African samples were analysed at a single laboratory in Durban (Global Clinical and Viral Laboratory). In Ghana, with the exception of iodine, all samples were analysed at a single laboratory in Accra (University of Ghana Chemical Pathology Laboratory in the School of Allied Health Sciences).

Urine samples for iodine analysis from both countries were stored at $-20^{\circ} \mathrm{C}$ and batch analysed using the Sandell-Kolthoff method with ammonium persulfate digestion and microplate reading ${ }^{36}$ at the North-West University Centre of Excellence for Nutrition. The laboratory participates successfully in the Program to Ensure the Quality of Urinary Iodine Procedures (EQUIP, US Centres for Disease Control and Prevention, Atlanta, Georgia, USA) ${ }^{37}$ A median of $<100 \mu$ g iodine $/ \mathrm{L}$ indicates population-level deficiency (there is no reference range for individuals). ${ }^{38}$

Even though there is no evidence that the addition of preserving substances such as $\mathrm{HCl}$ and thymol affects urinary iodine concentrations, ${ }^{39}$ we undertook testing to examine the influence of adding thymol or $\mathrm{HCl}$ to urine samples $(n=20)$ on urinary iodine concentrations. The results indicated no significant or relevant (below assay coefficient of variation) differences when compared with samples without added preservatives (results not shown here).

\section{Comparison of spot and 24-hour urine analyses}

The following equations will be used to assess the accuracy of using spot urine samples to assess 24-hour urinary sodium, potassium and iodine excretion: (1) Tanaka; ${ }^{40}$ (2) Kawasaki $^{41}$ and (3) INTERSALT. $^{42}$ The sensitivity of the formulae to estimate the measured 24-hour urinary creatinine, sodium and potassium excretion will be assessed using the receiver operator characteristic curve analysis. Multiple regression modelling will 
be conducted to determine whether new regression models are more appropriate for use in African populations.

\section{BP measurements}

Wrist-worn Omron BP devices were used to record three sequential measures on the left arm ( 1 min between each measure), with the wrist resting at the level of the heart and the respondent seated with legs uncrossed. The wrist BP devices are validated to the European Hypertension Society International Protocol. ${ }^{43}$

\section{Data capture, analysis and statistical power}

All data were and will be captured using an electronic data capture system and uploaded to a secure central server within each country. Cleaning and analysis of survey data are coordinated by the WHO. Based on the modelled estimated reduction of $0.85 \mathrm{~g}$ salt per day as a result of the legislation, with a current estimated South African population salt intake of $8.1 \mathrm{~g} /$ day $^{12}$ and a population variance of up to $35 \mathrm{~g}$ /day based on previous pilot data (unpublished), a sample size of 761 respondents would give $80 \%$ power to detect a significant difference (95\% CI). Allowing for error in 24-hour sample collection (incomplete or missing samples) in this complex field study, a target sample size of 1200 was chosen.

\section{ETHICS AND DISSEMINATION}

All respondents provide written informed consent prior to taking part in the study. The study complies with the ethical principles for medical research involving human participants as per the Declaration of Helsinki. ${ }^{46}$ Baseline data collection (for this nested substudy as part of wave 2) is complete and the results will be published in peer-reviewed international journals, presented at national and international conferences, and summarised in research and policy briefs. Completion of the first follow-up of the nested study (as part of SAGE wave 3) in South Africa and Ghana is expected by December 2017. Dissemination of the final results will begin soon thereafter. All de-identified data will be made available in the public domain.

\section{DISCUSSION}

The WHO recommends that adults consume no more than $5 \mathrm{~g}$ of salt per day ${ }^{47}$ while most South African adults consume well above this level, with bread being the single highest contributor to non-discretionary sodium intake. ${ }^{7}$ In the light of the high prevalence of hypertension within the country, ${ }^{3}$ the government's bold move to reduce sodium in bread, cereals, snacks, processed meats, spreads, soups, stocks and gravy in 2016, with further reductions mandated for 2019, is welcomed. This intervention could significantly reduce the prevalence of hypertension, stroke and CVD in South Africa, thereby substantially reducing healthcare costs to the state and to individuals. ${ }^{12}$ However, successful reduction of population level sodium intake through legislation has yet to be demonstrated.

The need to simultaneously monitor both sodium reduction and iodine status is required as, in South Africa, universal salt iodisation has successfully eradicated iodine deficiency. ${ }^{48} 49$ The two public health strategies are compatible ${ }^{50}$ if ongoing surveillance informs the adjustment of iodine levels in iodised salt as population salt intake decreases. ${ }^{51}$ The assessment of salt behaviours will be interesting, as multiple strategies accompany the sodium legislation, including mass media campaigns such as SaltWatch, which is coordinated by the Heart and Stroke Foundation South Africa, ${ }^{52}$ and primary care health education activities conducted by the South African (NDoH). All SAGE countries will include the standard salt behaviour questions in waves 2 and 3 so that a cross-national comparison of salt behaviours will be possible between the six LMIC countries.

\section{Assumptions and risks in the causal logic}

We make several assumptions within the implementation portion of the Results Chain model (figure 1) including the timely compliance of all manufacturers of the targeted food products with the sodium legislation; and that educational activities reach the intended beneficiaries.

South Africa is now one of a number of countries with mandatory sodium targets; others include Argentina, Belgium, Bulgaria, Greece, Hungary, the Netherlands, Paraguay and Portugal. ${ }^{6} 18$ Mandatory sodium targets in Argentina (Act 26905) came into force in December 2014 for three food groups: (1) meat and meat products; (2) soups, dressings and canned foods; and (3) farinaceous or starch containing products such as crackers, cookies and bakery products. ${ }^{53}$ There are strict penalties for not meeting the sodium regulations, ranging from fines to the confiscation of food products, and suspension of business for up to 5 years. ${ }^{53} \mathrm{~A}$ prepolicy evaluation conducted in February 2014 comparing food labels against the mandatory targets concluded that most foods in Argentina were already meeting the target sodium levels, though this differed by food category with around half of the bakery products reviewed exceeding the mandated sodium level. ${ }^{54}$ This high prelegislation compliance may be explained by the successful government-led programme 'Less salt, more life' initiated in Argentina in 2011, including voluntary agreements with the food industry to lower sodium in foods and extensive monitoring of both implementation (food sodium testing in independent laboratories) and effectiveness (sodium intake surveys and urinary sodium measurement). ${ }^{55}$ In contrast to this example is Belgium, where mandatory sodium levels in bread were set in 1985, although in 2006 half of the bakers were still producing bread with higher sodium levels, stating that tighter regulation led to products being imported and unfair competition from neighbouring European 
countries. ${ }^{56}$ Only after an awareness campaign was directed specifically at bakers did compliance increase to $90 \%$ by 2008, 13 years after the legislation was introduced.

Findings from Argentina also highlight that sodium discussions often take place between government and the bigger food companies and an ongoing challenge will be to determine compliance with sodium targets in small-sized and medium-sized food producers. ${ }^{54}$

These examples highlight the need for continued compliance monitoring, an understanding of the reasons for non-compliance, and clear interventions and penalties for non-compliance, as it would seem that compliance with legislation cannot be taken for granted.

Non-compliance by targeted food manufacturers or increased salt levels in non-legislated food products (by other food producers) are risks to undermining the intended outcomes. Educational activities that do not reach the intended beneficiaries are also a risk as they may fail in the message to modify discretionary salt use. Media campaigns to reduce salt can work, ${ }^{57}$ and the key again will be in documenting and monitoring their success. As a mitigation strategy for these risks, the SAGE South Africa team is working closely with stakeholders in government, academia, non-governmental organisations and research organisations who are directly involved in monitoring compliance and/or the development, delivery and evaluation of salt and BP educational activities. In September 2016, stakeholders met to develop a roadmap for the South African salt reduction strategy, with action points and a report due to be published. The meeting serves as a foundation to coordinate and link efforts. The authors will continue discussions with these stakeholders and are open to any discussions that promote a thorough and valid evaluation of the effectiveness of this important health policy.

Also, within the Results Chain model (figure 1), several assumptions underlie achieving the results including consumers purchase and consume the lower sodium products; educational activities are effective in changing behaviour to decreasing discretionary salt use; reduced salt intake is accurately reflected in a single 24-hour urine collection; reduced salt intake leads to reduced BP and ultimately a reduction in CVD events and healthcare spending. There is strong evidence supporting the final outcomes with high salt intakes associated with increased risk of stroke and $\mathrm{CVD}^{58} 59$ and population efforts to lower sodium intake producing notable improvements in BP and deaths from stroke and CVD. ${ }^{60}$ Naturally, this does not guarantee that we will find the same outcome. WHO-SAGE is well placed to continue follow-up in the South African cohort, as it has been operational in South Africa since 2003 with wave 0 of data collection, ${ }^{29}$ and plans to continue data collection after wave 3 (2017) approximately every 4 years. This provides an ideal opportunity to collect longer term data on cardiovascular and stroke mortality and morbidity in South Africa and Ghana.
In terms of acceptability of the lower sodium foods, one systematic review suggests that sodium levels can be reduced by up to $40 \%$ in bread and $70 \%$ in meat products without compromising consumer acceptability. ${ }^{61}$ Additionally, longer term exposure to lower salt foods has been shown to increase preference for those foods and decrease preference of higher salt alternatives. ${ }^{62} 63$ While it would appear that sodium regulations are unlikely to modify consumer purchasing behaviour, the WHO-SAGE South Africa team is also collaborating with organisations able to monitor consumer food purchasing patterns prelegislation and postlegislation.

There is evidence supporting salt reduction campaigns change behaviour and impact salt intake. For example, a community-based health education programme in Japan successfully decreased salt intake by $2-3 \mathrm{~g} /$ day. ${ }^{57} \mathrm{~A}$ campaign in the UK decreased discretionary salt use ${ }^{64}$ and reduced overall salt intake by around $10 \%{ }^{65}$ Again, monitoring and evaluation of educational activities within South Africa will be important to determine their effectiveness.

Finally, there is the question of whether one 24-hour urine collection is sufficient to assess dietary salt intake. There is little doubt that repeated 24-hour urine collection in an individual improves the accuracy to assess salt intake, with more collections giving greater accuracy. ${ }^{66}$ However, repeated sampling may lead to refusals or more incomplete samples ${ }^{67}$ producing underestimates of salt intake. ${ }^{68}$ Additionally, Mente $e t a l^{67}$ point out that large studies reduce random error, so that average estimates of salt intake from 24-hour urine collection across a large number of people are reliable estimates for groups, albeit less so for individuals. While repeated 24-hour urine collection may be feasible in smaller randomised controlled trials, it can be impractical for larger studies, especially in LMICs. ${ }^{69}$ Furthermore, 24-hour urine collection remains the gold standard to measure salt intake when compared with estimated intake from casual or spot urine samples. ${ }^{70}$ Therefore, a single, wellcollected 24-hour urine sample appears a pragmatic approach to take in this prospective cohort study of over 1000 participants in each of the two countries.

\section{Limitations of the study}

WHO SAGE is designed to investigate the health and ageing process in older ages; therefore, the focus is on adults aged 50 years and older. Although a smaller sample of adults aged 18-49years is included, the results from this study may not be representative for younger adult age groups. However, SAGE wave 1 data showed that four in every five adults above 50 years of age in South Africa are hypertensive, ${ }^{3}$ justifying a focus on monitoring the effectiveness of the sodium legislation within this age group. The gold standard method for estimating sodium intake is used (24-hour urinary $\mathrm{Na}$ excretion), yet the lack of comprehensive dietary assessment will not allow identification of major food contributors to total salt intake. Another limitation is 
our ability to effectively monitor the food industry adherence to the legislation. While we will work with key stakeholders to jointly evaluate the degree of enforcement observed and sodium content of food products, this is not the primary aim of the study. One potential limitation could be the choice of comparison group. Using Ghana provides a reasonable choice with some similar demographic and epidemiological characteristics and without formal national-level sodium legislation. While standard training and interview techniques as well as survey instruments were used, there was a difference of several months in the time frame for wave 2 data collections in South Africa and Ghana. It is unclear if this will impact the validity of comparisons. A clear analytical plan will be in place to facilitate interpretation of results by WHO-SAGE, SAGE-Ghana and SAGE-South Africa teams.

\section{Strengths of the study}

The comprehensive assessment of the ageing process within SAGE, alongside the rigorous random selection procedures employed, provides an ideal opportunity to assess the effectiveness of this legislative public health approach. Additionally, WHO SAGE is ideally placed for ongoing data collection to include evaluation of the planned 2019 legislative changes to further reduce sodium levels in foods and collection of data on hard end points such as cardiovascular-related mortality which require a longer time frame. WHO-SAGE measures BP in each wave of data collection and will continue to do this. While urinary sodium analysis is conducted only for waves 2 and 3 in the nested studies in South Africa and Ghana, from wave 2 onwards, questions on discretionary salt use have been added to SAGE for all respondents in each of the six countries. This will provide valuable data on self-reported discretionary salt behaviours as countries implement various strategies to reduce population salt intake.

Considering the burden of potentially preventable hypertension on health services in South Africa, the government's population-level advance towards making the food supply healthier is innovative. The current study adopts a novel approach to evaluate this public health policy in a cost-efficient and pragmatic manner, generating information relevant to other countries, as sodium legislation is increasingly being adopted by governments across the globe.

\footnotetext{
Author affiliations

${ }^{1}$ School of Medicine, University of Wollongong, Wollongong, New South Wales, Australia

${ }^{2}$ Hypertension in Africa Research Team (HART), North-West University, Potchefstroom, South Africa

${ }^{3}$ Department of Community Health, University of Ghana, Legon, Ghana

${ }^{4}$ World Health Organization (WHO), Geneva, Switzerland

${ }^{5}$ Global Clinical \& Viral Laboratories, Durban, South Africa

${ }^{6}$ Centre of Excellence for Nutrition, North-West University, Potchefstroom, South Africa

${ }^{7}$ Chemical Pathology Unit, Department of Medical Laboratory Sciences, University of Ghana, Legon, Ghana

${ }^{8}$ Vassar College, Poughkeepsie, New York, USA
}

${ }^{9}$ MRC Research Unit for Hypertension and Cardiovascular Disease, NorthWest University, Potchefstroom, South Africa

${ }^{10}$ University of Newcastle Research Centre for Generational Health and Ageing, Newcastle, New South Wales, Australia

Acknowledgements The authors would like to acknowledge Dr Stephen Rule, Dr Robin Richards and Godfrey Dlulane of Outsourced Insight who were subcontracted to conduct the surveys and coordinate data collection within South Africa.

Contributors KC, PK and NN designed research. LJW, RBB, EM, CP and AES implemented research. $\mathrm{S}(\mathrm{L}) \mathrm{M}, \mathrm{GAA}, \mathrm{JB}$ and $\mathrm{ET}$ were responsible for laboratory analyses. KC, PK and LJW were equal contributors to the paper drafting. All authors reviewed and approved the final version. KC and PK have primary responsibility for final content. All authors read and approved the final manuscript.

Funding This work is supported by an agreement with the CDC Foundation with financial support provided by Bloomberg Philanthropies and a Partnerships \& Research Development Fund (PRDF) grant from the Australia Africa Universities Network. SAGE is supported by the WHO and the Division of Behavioral and Social Research (BSR) at the National Institute on Aging (NIA), US National Institutes of Health, through Interagency Agreements (OGHA 04034785; YA1323-08-CN-0020; Y1-AG-1005-01) with the WHO and a Research Project Grant 1 R01 AG034479.

Disclaimer The content of this manuscript is solely the responsibility of the authors and does not necessarily represent the official views of the WHO or the funding bodies. KC takes responsibility for the contents of this article.

\section{Competing interests None.}

Ethics approval The WHO Ethics Review Committee approved the study (RPC149). Local ethical approval was obtained from the North-West University Human Research Ethics Committee (Potchefstroom, South Africa), University of the Witwatersrand Human Research Ethics Committee (Johannesburg, South Africa), and University of Ghana Medical School Ethics and Protocol Review Committee (Accra, Ghana).

Provenance and peer review Not commissioned; externally peer reviewed.

Open Access This is an Open Access article distributed in accordance with the terms of the Creative Commons Attribution (CC BY 4.0) license, which permits others to distribute, remix, adapt and build upon this work, for commercial use, provided the original work is properly cited. See: http:// creativecommons.org/licenses/by/4.0/

\section{REFERENCES}

1. Forouzanfar MH, Alexander L, Anderson HR, et al. Global, regional, and national comparative risk assessment of 79 behavioural, environmental and occupational, and metabolic risks or clusters of risks in 188 countries, 1990-2013: a systematic analysis for the Global Burden of Disease Study 2013. Lancet 2015;386:2287-323.

2. Yusuf S, Rangarajan S, Teo K, et al. Cardiovascular risk and events in 17 low-, middle-, and high-income countries. N Engl J Med 2014;371:818-27.

3. Lloyd-Sherlock P, Beard J, Minicuci N, et al. Hypertension among older adults in low- and middle-income countries: prevalence, awareness and control. Int J Epidemiol 2014;43:116-28.

4. Day C, Groenewald P, Laubscher R, et al. Monitoring of non-communicable diseases such as hypertension in South Africa: challenges for the post-2015 global development agenda. S Afr Med J 2014;104:680-7.

5. Webster JL, Dunford EK, Hawkes C, et al. Salt reduction initiatives around the world. J Hypertens 2011;29:1043-50.

6. Trieu $\mathrm{K}$, Neal B, Hawkes $\mathrm{C}$, et al. Salt reduction initiatives around the world: a systematic review of progress towards the global target. PLOS ONE 2015;10:e0130247.

7. Charlton KE, Steyn K, Levitt NS, et al. Diet and blood pressure in South Africa: intake of foods containing sodium, potassium, calcium, and magnesium in three ethnic groups. Nutrition 2005;21:39-50.

8. Charlton K, Webster J, Kowal P. To legislate or not to legislate? A comparison of the UK and South African approaches to the development and implementation of salt reduction programs. Nutrients 2014;6:3672-95. 
9. Charlton KE, Steyn K, Levitt NS, et al. Ethnic differences in intake and excretion of sodium, potassium, calcium and magnesium in South Africans. Eur J Cardiovasc Prev Rehabil 2005;12:355-62.

10. Charlton KE, Steyn K, Levitt NS, et al. A food-based dietary strategy lowers blood pressure in a low socio-economic setting: a randomised study in South Africa. Public Health Nutrition 2008;11:1397-406.

11. Foodstuffs, cosmetics and disinfectants Act, 1972 (Act 54 of 1972). Regulations relating to the reduction of sodium in certain foodstuffs and related matters. South African Department of Health, 2013. http://www.heartfoundation.co.za/sites/default/files/articles/South\% 20Africa\%20salt\%20legislation.pdf (accessed March 2016).

12. Bertram Y, Steyn K, Wentze-Viljoen E, et al. Reducing the sodium content of high-salt foods: Effect on cardiovascular disease in South Africa. S Afr Med J 2012;102:743-5.

13. Watkins DA, Olson ZD, Verguet S, et al. Cardiovascular disease and impoverishment averted due to a salt reduction policy in South Africa: an extended cost-effectiveness analysis. Health Policy Plan 2016;31:75-82.

14. Verkaik-Kloosterman J, van 't Veer P, Ocké MC. Reduction of salt: will iodine intake remain adequate in the Netherlands? Br J Nutr 2010;104:1712-18.

15. Yang Q, Liu T, Kuklina EV, et al. Sodium and potassium intake and mortality among us adults: prospective data from the third national health and nutrition examination survey. Arch Intern Med 2011;171:1183-91.

16. Cappuccio F, Capewell S. Facts, issues and controversies in salt reduction for the prevention of cardiovascular disease. Funct Food Rev 2015;7:41-61.

17. He FJ, Brinsden HC, MacGregor GA. Salt reduction in the United Kingdom: a successful experiment in public health. J Hum Hypertens 2014;28:345-52.

18. Webster J, Trieu K, Dunford E, et al. Target salt 2025: a global overview of national programs to encourage the food industry to reduce salt in foods. Nutrients 2014;6:3274-87.

19. Gertler PJ, Martinez S, Premand P, et al. Impact evaluation in practice. Washington DC, USA: The World Bank, 2011.

20. Thow AM, Sanders D, Drury E, et al. Regional trade and the nutrition transition: opportunities to strengthen NCD prevention policy in the Southern African development community. Global Health Action 2015;8:28338.

21. Emongor R, Kirsten J. The impact of South African supermarkets on agricultural development in the SADC: a case study in Zambia, Namibia and Botswana. Agrekon 2009;48:60-84.

22. Trade report: export opportunities for South Africa in selected African countries. Department of research and information. Sandton, South Africa: 2014. http://www.idc.co.za/images/2014/pdfs/IDC\%20R\&1\% 20publication\%20-\%20Export\%20opportunities\%20for\%20SA\%20in $\% 20$ select\%20African\%20countries.pdf (accessed Sep 2016).

23. Bosu WK. Epidemic of hypertension in Ghana: a systematic review. BMC Public Health 2010;10:418.

24. 'Smart salt' reduces iodine deficiency in Ghana (2012) UNICEF. 2012. http://www.unicef.org/health/ghana_61446.html (accessed Sep 2016)

25. Mensah JT, Botchway E. Ghana's salt industry: a neglected sector for economic development? Resour Policy 2013;38:288-94.

26. Affam M, Asamoah D. Economic potential of salt mining in Ghana towards the oil find. Res J Environ Earth Sci 2011;3:448-56.

27. Oyebode O, Oti S, Chen YF, et al. Salt intakes in sub-Saharan Africa: a systematic review and meta-regression. Popul Health Metr 2016;14:1-14

28. Cappuccio FP, Kerry SM, Micah FB, et al. A community programme to reduce salt intake and blood pressure in Ghana [ISRCTN88789643]. BMC Public Health 2006;6:1.

29. Kowal P, Chatterji S, Naidoo N, et al. Data resource profile: the World Health Organization Study on global AGEing and adult health (SAGE). Int J Epidemiol 2012;41:1639-49.

30. Üstün TB, Chatterii S, Mechbal A, et al. The world health surveys. Health systems performance assessment: debates, methods and empiricism. Geneva, Switzerland: World Health Organization, 2003. http://www.who.int/healthinfo/survey/hspa58.pdf (accessed Mar 2016)

31. WHO/PAHO Regional Expert Group for Cardiovascular Disease Prevention through Population-wide Dietary Salt Reduction. Protocol for population level sodium determination in 24-hour urine samples. Geneva: World Health Organization, 2010. http://www.paho.org/hq/ index.php?option=com docman\&task=doc view\&gid=21488\&ltemid (accessed Mar 2016)

32. Nicar MJ, Hsu MC, Johnson T, et al. The preservation of urine samples for determination of renal stone risk factors. Lab Med 1987;18:382-4.
33. Stolarz-Skrzypek K, Kuznetsova T, Thijs L, et al. Fatal and nonfatal outcomes, incidence of hypertension, and blood pressure changes in relation to urinary sodium excretion. JAMA 2011;305:1777-85.

34. Bingham $\mathrm{S}$, Cummings $\mathrm{JH}$. The use of 4-aminobenzoic acid as a marker to validate the completeness of $24 \mathrm{~h}$ urine collections in man. Clin Sci 1983;64:629-35.

35. Jakobsen J, Pedersen AN, Ovesen L. Para-aminobenzoic acid (PABA) used as a marker for completeness of 24 hour urine: effects of age and dosage scheduling. Eur J Clin Nutr 2003;57:138-42.

36. Ohashi T, Yamaki M, Pandav CS, et al. Simple microplate method for determination of urinary iodine. Clin Chem 2000;46:529-36.

37. Caldwell KL, Makhmudov A, Jones RL, et al. EQUIP: a worldwide program to ensure the quality of urinary iodine procedures. Accreditation Qual Assur 2005;10:356-61.

38. Delange $\mathrm{F}$, de Benoist $\mathrm{B}$, Burgi $\mathrm{H}$. Determining median urinary iodine concentration that indicates adequate iodine intake at population level. Bull World Health Organ 2002;80:633-6.

39. Sullivan KM, May S, Maberly G. Urinary iodine assessment: a manual on survey and laboratory methods. Atlanta, USA, 2000. http://www.ceecis.org/iodine/10_monitoring/02_monitoring_iodine_ status/mon_uri_pammunicef_2002.pdf (accessed Mar 2016).

40. Tanaka T, Okamura T, Miura K, et al. A simple method to estimate populational 24-h urinary sodium and potassium excretion using a casual urine specimen. J Hum Hypertens 2002;16:97-103.

41. Kawasaki T, Itoh K, Uezono K, et al. A simple method for estimating 24 $\mathrm{h}$ urinary sodium and potassium excretion from second morning voiding urine specimen in adults. Clin Exp Pharmacol Physiol 1993;20:7-14.

42. Brown IJ, Dyer AR, Chan Q, et al. Estimating 24-hour urinary sodium excretion from casual urinary sodium concentrations in western populations: the INTERSALT study. Am J Epidemiol 2013;177:1180-92.

43. O'Brien E, Pickering T, Asmar R, et al. Working group on blood pressure monitoring of the European society of hypertension international protocol for validation of blood pressure measuring devices in adults. Blood Press Monit 2002;7:3-17.

44. Bull FC, Maslin TS, Armstrong T. Global physical activity questionnaire (GPAQ): nine country reliability and validity study. $J$ Phys Act Health 2009;6:790.

45. The Whoqol Group. World Health Organization quality of life assessment (WHOQOL): development and general psychometric properties. Soc Sci Med 1998:46:1569-85.

46. World Medical Association. World Medical Association Declaration of Helsinki ethical principles for medical research involving human subjects. JAMA 2013;310:2191-4.

47. World Health Organization. WHO Guideline: sodium intake for adults and children. Geneva: World Health Organization, 2012. http://www. who.int/nutrition/publications/guidelines/sodium intake/en/ (accessed Mar 2016)

48. Kalk W, Paiker J, Van Arb M, et al. Dietary iodine deficiency in South Africa. Surveys before the introduction of universal salt iodisation. S Afr Med J 1998;88:357-8.

49. Jooste $\mathrm{PL}$, Labadarios $\mathrm{D}, \mathrm{Nel} \mathrm{H}$, et al. lodine content of household salt, drinking water and iodine status of women and children. In: Labadarios D. National food consumption survey: fortification baseline, Chapter 8: South Africa 2005. Stellenbosch: Department of Health; 2007:387-407.

50. Charlton KE, Jooste PL, Steyn K, et al. A lowered salt intake does not compromise iodine status in Cape Town, South Africa, where salt iodization is mandatory. Nutrition 2013;29:630-4.

51. Aburto N, Abudou M, Candeias V, et al. Effect and safety of salt iodization to prevent iodine deficiency disorders: a systematic review with meta-analyses. WHO eLibrary of Evidence for Nutrition Actions (eLENA). Geneva. 2014. http://apps.who.int/iris/bitstream/10665/ 148175/1/9789241508285_eng.pdf (accessed Mar 2016).

52. Eksteen G. Salt intake in South Africa: a current perspective. $J$ Endocrinol Metab Diabetes S Afr 2015;20:9-12.

53. LEY 26.905. Promoción de la reducción del consumo de sodio en la población. Buenos Aires, Argentina. 2013. http://www.boletinoficial. gov.ar/DisplayPdf.aspx?s=01\&f=20131216 (accessed Sep 2016)

54. Allemandi L, Tiscornia MV, Ponce M, et al. Sodium content in processed foods in Argentina: compliance with the National Law. Cardiovasc Diagn Ther 2015;5:197-206.

55. Ministerio de Salud, Presidencia de la Nación, Argentina. Argentine initiative to reduce sodium consumption "Less Salt, More Life". Ministerio de Salud, Argentina: Pan American Health Organization, 2012. http://www2.paho.org/panamericanforum/wp-content/uploads/ 2012/08/less-salt-more-life_PAHO-consortium_ARG.pdf (accessed Sep 2016)

56. Wagemans K. Salt and bread: a good marriage? Position of the Belgian bread sector. Report produced for the European 
Commission Directorate General for Health and Consumers. 2009. http://ec.europa.eu/health/nutrition_physical_activity/docs/ ev20091021_wagemans_en.pdf (accessed Sep 2016).

57. Yokota K, Harada M, Wakabayashi Y, et al. [Evaluation of a community-based health education program for salt reduction through media campaigns]. Nihon Koshu Eisei Zasshi 2006;53:543-53.

58. Strazzullo P, D'Elia L, Kandala NB, et al. Salt intake, stroke, and cardiovascular disease: meta-analysis of prospective studies. BMJ 2009;339:b4567.

59. Shulkin ML, Micha R, Rao M, et al. Abstract P279: major dietary risk factors for cardiometabolic disease: current evidence for causal effects and effect sizes from the Global Burden of Diseases (GBD) 2015 study. Circulation 2016;133(Suppl 1):AP279-AP79.

60. He FJ, Pombo-Rodrigues S, MacGregor GA. Salt reduction in England from 2003 to 2011: its relationship to blood pressure, stroke and ischaemic heart disease mortality. BMJ Open 2014;4:e004549.

61. Jaenke R, Barzi F, McMahon E, et al. Consumer acceptance of reformulated food products: a systematic review and meta-analysis of salt-reduced foods. Crit Rev Food Sci Nutr 2016. http://dx.doi.org/ 10.1080/10408398.2015.1118009 (accessed Sep 2016).

62. Bertino M, Beauchamp GK, Engelman K. Long-term reduction in dietary sodium alters the taste of salt. Am J Clin Nutr 1982;36:1134-44.
63. Beauchamp GK, Bertino M, Engelman K. Modification of salt taste. Ann Intern Med 1983:98:763-9.

64. Sutherland J, Edwards P, Shankar B, et al. Fewer adults add salt at the table after initiation of a national salt campaign in the UK: a repeated cross-sectional analysis. Br J Nutr 2013;110:552-8.

65. Shankar B, Brambila-Macias J, Traill B, et al. An evaluation of the UK Food Standards Agency's salt campaign. Health Econ 2013;22:243-50.

66. Lerchl K, Rakova N, Dahlmann A, et al. Agreement between 24-hour salt ingestion and sodium excretion in a controlled environment. Hypertension 2015:66:850-7.

67. Mente A, O'Donnell MJ, Yusuf S. Measuring sodium intake in populations: Simple is best? Am J Hypertens 2015;28: 1303-5.

68. Wielgosz A, Robinson $\mathrm{C}, \mathrm{Mao} \mathrm{Y}$, et al. The impact of using different methods to assess completeness of 24-hour urine collection on estimating dietary sodium. J Clin Hypertens (Greenwich) 2016;18:581-4.

69. O'Donnell M, Mente A, Yusuf S. Sodium intake and cardiovascular health. Circ Res 2015;116:1046-57.

70. Ji C, Sykes L, Paul C, et al. Systematic review of studies comparing 24-hour and spot urine collections for estimating population salt intake. Rev Panam Salud Publica 2012;32:307-15. 